\title{
ZMYND10, an epigenetically regulated tumor suppressor, exerts tumor-suppressive functions via miR145-5p/NEDD9 axis in breast cancer
}

Yan Wang ${ }^{1+}$, Liangying Dan ${ }^{1,2+}$, Qianqian $\mathrm{Li}^{1}$, Lili Li ${ }^{3}$, Lan Zhong ${ }^{3}$, Bianfei Shao ${ }^{1}$, Fang Y Y ${ }^{1}$, Sanxiu He ${ }^{1}$, Shaorong Tian', Jin He${ }^{1}$, Qian Xiao ${ }^{1}$, Thomas C. Putti ${ }^{4}$, Xiaoqian He ${ }^{1}$, Yixiao Feng ${ }^{1}$, Yong Lin ${ }^{5}$ and Tingxiu Xiang ${ }^{1 *}$ (D)

\begin{abstract}
Background: Recent studies suggested that ZMYND10 is a potential tumor suppressor gene in multiple tumor types. However, the mechanism by which ZMYND10 inhibits breast cancer remains unclear. Here, we investigated the role and mechanism of ZMYND10 in breast cancer inhibition.

Results: ZMYND10 was dramatically reduced in multiple breast cancer cell lines and tissues, which was associated with promoter hypermethylation. Ectopic expression of ZMYND10 in silenced breast cancer cells induced cell apoptosis while suppressed cell growth, cell migration and invasion in vitro, and xenograft tumor growth in vivo. Furthermore, molecular mechanism studies indicated that ZMYND10 enhances expression of miR145-5p, which suppresses the expression of NEDD9 protein through directly targeting the 3'-untranslated region of NEDD9 mRNA.

Conclusions: Results from this study show that ZMYND10 suppresses breast cancer tumorigenicity by inhibiting the miR145-5p/NEDD9 signaling pathway. This novel discovered signaling pathway may be a valid target for small molecules that might help to develop new therapies to better inhibit the breast cancer metastasis.
\end{abstract}

Keywords: ZMYND10, Breast cancer, NEDD9, miR145-5p

\section{Background}

Breast cancer $(\mathrm{BC})$ is the most frequently diagnosed cancer and the leading cause of cancer death among females worldwide, with an estimated 1,762,450 cases and 606, 880 deaths in 2019. Breast cancer alone accounts for $30 \%$ of all cancer cases and $15 \%$ of all cancer deaths among females [1]. In recent years, female breast cancer mortality rates have decreased or remained stable in the western countries, while in China the mortality rates are on the rise [2]. Breast cancer is an extremely heterogeneous disease with varying clinical manifestations and treatment responses [3]. Hence, clinical challenges in the treatment of breast cancer patients remain and it is

\footnotetext{
* Correspondence: xiangtx@cqmu.edu.cn

†Yan Wang and Liangying Dan contributed equally to this work.

${ }^{1}$ Key Laboratory of Molecular Oncology and Epigenetics, The First Affiliated

Hospital of Chongqing Medical University, Chongqing, China

Full list of author information is available at the end of the article
}

inevitable that new biomarkers will have to be identified on an individual basis.

$Z M Y N D 10$, also known as BLU (zinc finger, MYNDtype containing 10 ), encodes a $50-\mathrm{kD}$ protein containing an MYND-type zinc finger DNA-binding domain in the C-terminus that is commonly found in transcription repressors [4]. ZMYND10 is located to the $3 \mathrm{p} 21.3$ region, and is frequently inactivated or downregulated via genetic or epigenetic changes in many solid tumors, such as lung cancer [5, 6], glioma tumors [7], ovarian cancer [8], liver cancer [9], esophageal squamous cell carcinomas [10], neuroblastoma [11], myelodysplastic syndrome [12], gastric cancer [13], and nasopharyngeal cancer [14]. In recent decades, documented studies have confirmed that ZMYND10 is a tumor suppressor that can induce apoptosis [8, 15], arrest cell cycle [16], and inhibit proliferation and angiogenesis [17] in different tumors. Some reports have shown that ZMYND10 can sensitize 
anticancer activities of chemotherapeutic agents such as gemcitabine [18] and paclitaxel [19]. Although it has been suggested that ZMYND10 downregulation or silencing is closely correlated to its promoter CpG methylation, its biological functions and molecular mechanisms in breast cancer remain unknown.

NEDD9 (also known as HEF1 and CasL) is a prometastatic gene that is upregulated in different metastatic cancers [20]. It is a cytoplasmic multi-domain scaffolding protein required for mesenchymal invasion and migration driven by extracellular matrix proteolysis. NEDD9 downregulation has been shown to dramatically reduce cell invasion and metastasis in multiple tumors including breast cancer [21].

In this study, we found that ZMYND10 suppresses breast cancer tumorigenicity through upregulating miR145-5p to inhibit the expression of oncogene NEDD9, which results in suppression of cell invasion and migration and breast cancer progression.

\section{Results \\ ZMYND10 downregulation in breast cancer is associated with poor patient survival}

To investigate whether ZMYND10 is downregulated in breast cancer, we first used immunohistochemistry assay to examine its expression in tumor-adjacent $(n=16)$ and tumor tissues $(n=27)$. ZMYND10 expression was significantly lower in breast tumor samples(22/27) than in breast tumor-adjacent tissues (Table 1, Fig. 1a). Furthermore, the ZMYND10 mRNA expression level was detected by $\mathrm{qPCR}$ in paired breast tumor and adjacent non-tumor tissues with different ER/PR/HER2 statuses. $Z M Y N D 10$ mRNA levels were much lower in breast cancer tissues than that in normal breast tissue in basallike (ER-/PR-/HER2-) tumors (14/16). There were no statistical differences in luminal $(\mathrm{ER}+/ \mathrm{PR}+/ \mathrm{HER} 2-$ or $\mathrm{ER}+/ \mathrm{PR}+/$ HER2 +$)$ tumors $(n=36$, Fig. 1b). Gene Expression-Based Outcome for Breast Cancer Online (GOBO) (http://co.bmc.lu.se/gobo) database showed consistent results, in which the expression of ZMYND10 was lower in tri-negative (ER-/PR-/HER2-) tumors compared to that in other molecular type tumors, and was closely related to tumor grade (Fig. 1c-e). Significantly, the prognostic analysis indicated that higher expression of ZMYND10 was related to better patient survival, which was detected in an integrated database with 3951 cases from the Kaplan-Meier Plotter and in

Table 1 ZMYND10 protein expression in breast cancer and adjacent tissues

\begin{tabular}{lllll}
\hline Tissue & Samples & Positive & Negative & $p$ value \\
\hline Breast cancer tissues & 27 & 5 & 22 & 0.0181 \\
BC surgical margin tissues & 16 & 9 & 7 & \\
\hline
\end{tabular}

Note: $B C$, breast cancer
1379 samples from GOBO (Fig. 1f). Together, these data demonstrated a reduction in ZMYND10 expression in breast cancer, which may be an indicator of breast cancer prognosis.

\section{Promoter methylation of ZMYND10 contributes to its downregulation in breast cancer}

DNA methylation is a key mechanism that represses the expression of tumor suppressor genes in cancer. Thus, a possible link between promoter methylation and downregulation of ZMYND10 expression in breast cancer was investigated. $Z M Y N D 10$ was significantly reduced in multiple breast cancer cell lines (7/10), but broadly expressed in all normal breast tissue. MSP analysis showed that ZMYND10 CpG island was methylated in 80\% (8/10) of breast cancer cell lines (Fig. 2a). To further determine whether promoter methylation directly mediates $Z M Y N D 10$ silencing, we tested whether ZMYND10 expression can be restored by pharmacological demethylation in ZMYND10-downregulated breast cancer cell lines MDA-MB231 and SK-BR-3 via treating with the DNA methyltransferase inhibitor Aza and histone deacetylase inhibitor TSA. The expression of ZMYND10 was restored after Aza treatment without or with TSA in MDA-MB231 and SK-BR-3 cell lines.

Meanwhile, the results of quantitative methylationspecific PCR (qMSP) showed that the methylation level of ZMYND10 was decreased and the un-methylation level of ZMYND10 was increased (Fig. 2b).

MSP was used to examine ZMYND10 methylation in 138 primary breast cancer tissue, 40 breast canceradjacent tissue, 46 breast fringe, and 8 normal breast tissue samples. ZMYND10 promoter methylation was detected in 101 of 138 (73\%) breast cancer tissue samples, but not in normal breast tissues (0/8, Fig. 2c,Table 2). Bisulfite genomic sequencing was then used to measure the methylation of ZMYND10 CpG in MB468 and MDA-MB231 cells treated with Aza and TSA and twopaired normal breast and breast tumor tissue samples, which verified the MSP results (Fig. 2d, e).

The association of ZMYND10 promoter methylation and patient clinicopathological features was analyzed, which clearly showed that ZMYND10 methylation was not statistically connected to age, histological type, tumor size, lymph node metastasis, or PR, ER, and HER2 breast cancer patient status (data not shown). These data indicated that ZMYND10 promoter methylation was common in breast cancer tissues, which is maybe an underlying biomarker for early detection of breast cancer.

\section{Overexpression of ZMYND10 inhibited colony formation and proliferation of breast cancer cells}

Silencing of ZMYND10 by promoter methylation in breast cancer cell lines as well as primary tumors suggested 


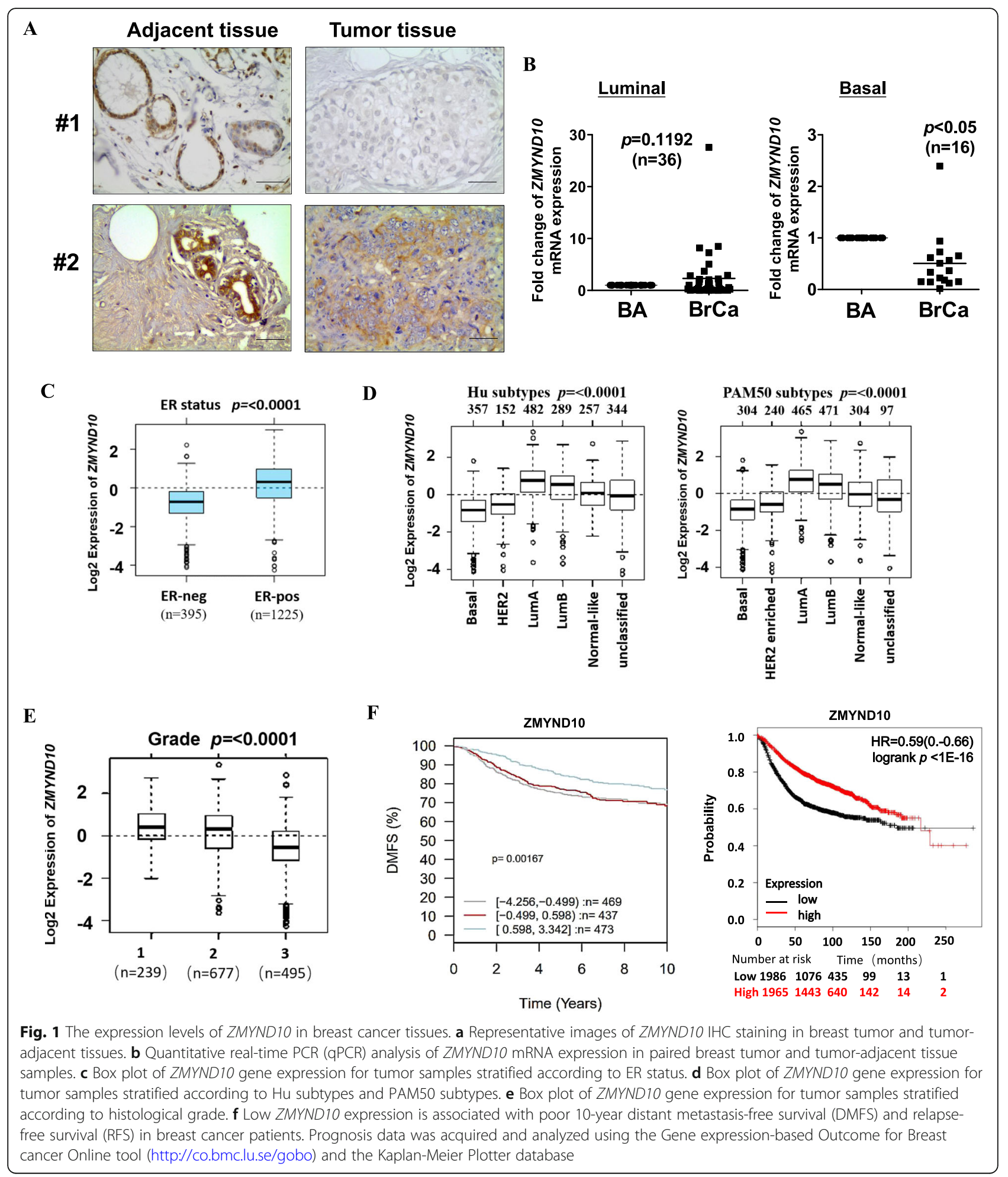

$Z M Y N D 10$ as a functional tumor suppressor in breast cancer. Therefore, MDA-MB231(ER-/PR-/HER2-) and SK-BR-3(ER -/PR-/HER2+) cell lines with low expression of ZMYND10 were selected for a series of functional experiments in vitro. Colony formation and MTS assays were used to evaluate the
ZMYND10 suppressor function. The overexpression of ZMYND10 in MDA-MB231 and SK-BR-3 cells was detected by RT-PCR and western blot (Fig. 3a, b). When ZMYND10 was overexpressed, the growth of MDA-MB231 and SK-BR-3 cells was strongly inhibited at 48 and $72 \mathrm{~h}(p<0.001$, Fig. 3c). 


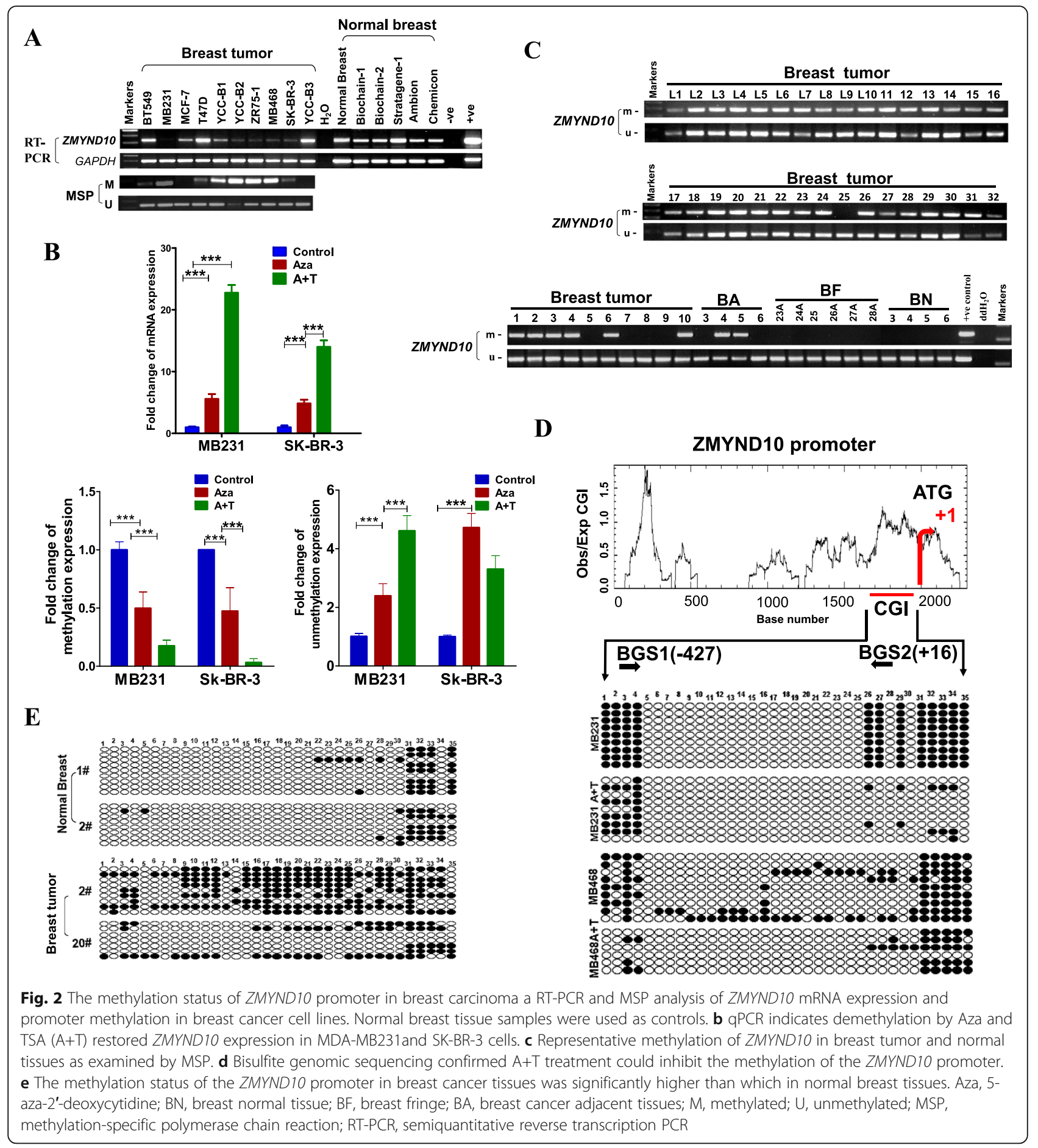

Table 2 Methylation status of ZMYND10 promoter in primary breast tumors

\begin{tabular}{llll}
\hline Samples & \multicolumn{2}{l}{ ZMYND10 promoter } & $\begin{array}{l}\text { Frequency of } \\
\text { methylation }\end{array}$ \\
\cline { 2 - 3 } & Methylation & Unmethylation & \\
\hline BC $(n=138)$ & 101 & 37 & $101 / 138(73 \%)$ \\
BN $(n=8)$ & 0 & 8 & $0 / 8(0 \%)$ \\
\hline
\end{tabular}

Note: $B C$, breast cancer; $B N$, breast normal tissues
Smaller and fewer colonies were formed in MDA-MB231 and SK-BR-3 cells expressing ZMYND10 than that in the empty vector group $(p<0.001$, Fig. 3d, e).

ZMYND10 induces cell cycle arrest in the G2/M phase and promotes apoptosis of breast tumor cells

To explore the effects of ZMYND10 on cell cycle progression, flow cytometry analysis was performed. The 


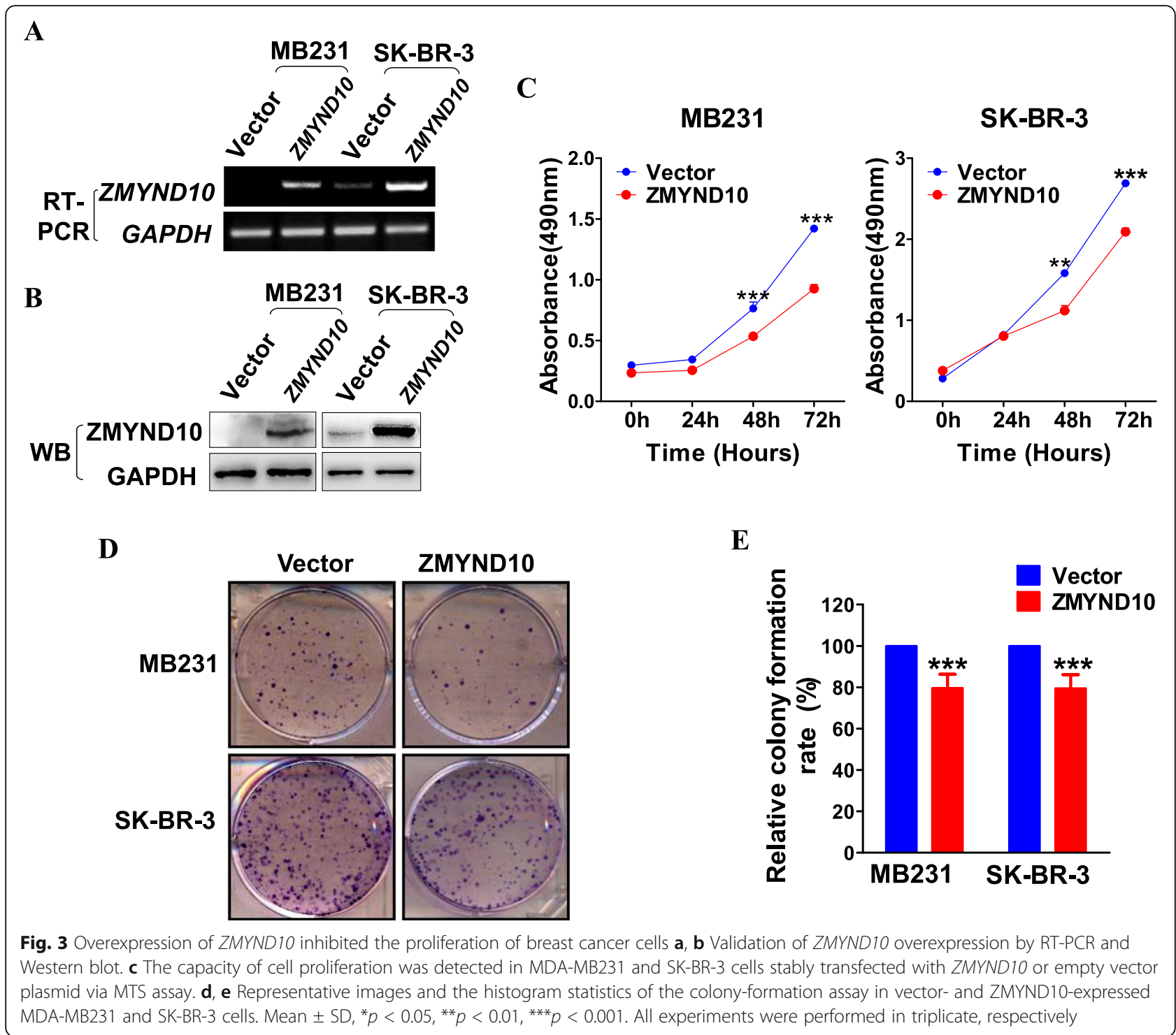

results showed that increased cell accumulation in the G2/M phase ZMYND10-transfected cells (vector control vs $Z M Y N D 10=14.6 \%$ vs $28.6 \%$ in MDA-MB231 cells, $p<$ 0.005 ; and $10.3 \%$ vs $16.3 \%$ in SK-BR-3 cells, $p<0.005$, Fig. 4 a). Western blot analysis was used to examine the expression of cell cycle-related proteins. While ZMYND10 upregulated the expression of protein p27 and protein p21 in MDA-MB231 cells and SK-BR-3 cells, cyclin D1 protein expression was suppressed in ZMYND10-transfected cells (Fig. 4b). Annexin V-FITC/PI staining assays were performed to examine apoptosis. Annexin V-PI-positive cells were increased in ZMYND10-transfected MDA-MB231 and SK-BR-3 cells to $36.98 \%$ and $8.19 \%$, respectively, compared with the controls ( $p$ $<0.01$, Fig. 4c), suggesting that ZMYND10 can accelerate cell apoptosis. Furthermore, western blot analysis showed that ectopic ZMYND10 downregulated anti-apoptotic proteins Bcl$\mathrm{xL}$ and $\mathrm{Bcl}-2$ and upregulated the pro-apoptotic protein Bax, cleaved caspase-3, and cleaved PARP in both MDA-MB231 and SK-BR-3 cells (Fig. 4d). These results indicated that ZMYND10 suppresses cell proliferation through inducing G2/ $\mathrm{M}$ cell cycle arrest and apoptosis.

Ectopic ZMYND10 expression inhibits breast cancer cell migration and invasion

A wound-healing assay was performed to investigate whether ZMYND10 suppresses tumor cell migration. Ectopic expression of ZMYND10 significantly inhibited cell migration from the wound edges compared to the vector control (Fig. 5a). Transwell assay demonstrated a corresponding reduction of migration and invasion in ZMYND10-overexpressing cells compared to that in vector-transfected cells $(p<0.01$, Fig. 5b, c). These results suggested that ZMYND10 had the capacity to inhibit migration and invasion in vitro. 


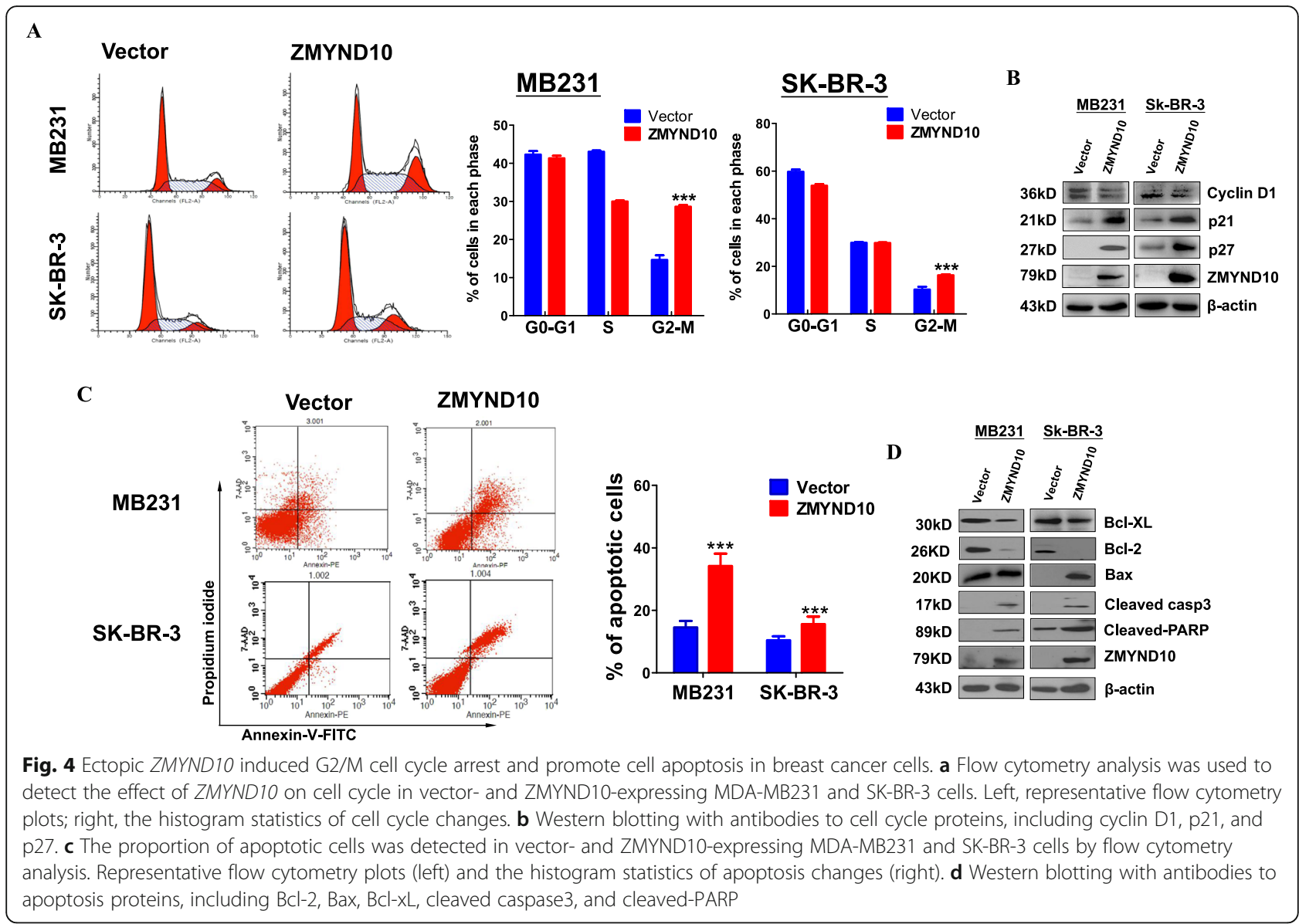

ZMYND10 regulates pathways related to focal adhesion in breast cancer cells

To further study the biological mechanism by which ZMYND10 suppresses the development of breast cancer, gene expression profiles between the control cells and ZMYND10-overexpressing cells were compared using RNA-Sequencing (RNA-Seq). There were 392 differentially expressed genes (DEGs) identified, among which 156 were upregulated and 236 were downregulated (fold change $>2$, FDR (false discovery rate) $<0.05$, Additional file 1: Figure $\mathrm{S} 1 \mathrm{~A}]$. The major identified biological pathways included the focal adhesion, PPAR, and MAPK signaling pathways (Additional file 1: Figure S1B).

\section{ZMYND10 inhibits breast cancer by suppressing NEDD9 expression}

Screening of differentially expressed genes in the focal adhesion pathway leads the focus to NEDD9 that is closely related to breast cancer metastasis (Additional file 1: Figure $\mathrm{S} 1 \mathrm{C}$ ). qPCR assay was performed to confirm the inhibitory effect of ZMYND10 on NEDD9 expression in breast cancer cells (Fig. 6a). And the negative regulatory effect of ZMYND10 on NEDD9 was also verified via dualluciferase reporter assay. These data indicated that
ZMYND10 obviously repressed luciferase reporter activity of NEDD9 (Fig. 6b). By immunofluorescence detected with laser scanning confocal microscopy, reduced NEDD9 expression was seen in ZMYND10-expressing cells than in the control cells at different time points (Fig. 6c). Because ZMYND10 was reported to inhibit PI3K/AKT [19] and NEDD9 participated in AKTactivation in certain circumstances [22], we examined if ZMYND10 affects this pathway in breast cancer. As expected, NEDD9,p-PI3K, and $p-A K T$ were significantly down-regulated while $p$ GSK3 $\beta$ was markedly upregulated in ZMYND10-transfected cells (Fig. 6d). The results clearly showed that ZMYND10 could inhibit the PI3K/AKT pathway in breast cancer cells. Since NEDD9 belongs to the Cas family of non-catalytic scaffold proteins, it controls cell survival, cell cycle, migration, and adhesion signals. And NEDD9 was reported to affect the lysosomal degradation of E-cadherin by regulating $S R C$ kinase [23], we examined a number of proteins that were involved in EMT (epithelial-mesenchymal transformation ) process. The data showed that ZMYND10 inhibited the process of EMT. In a rescue experiment, overexpression of NEDD9 partially attenuated the ability of ZMYND10 in inhibiting migration and invasion of breast cancer cells (Fig. 7a, b). Altogether, the 


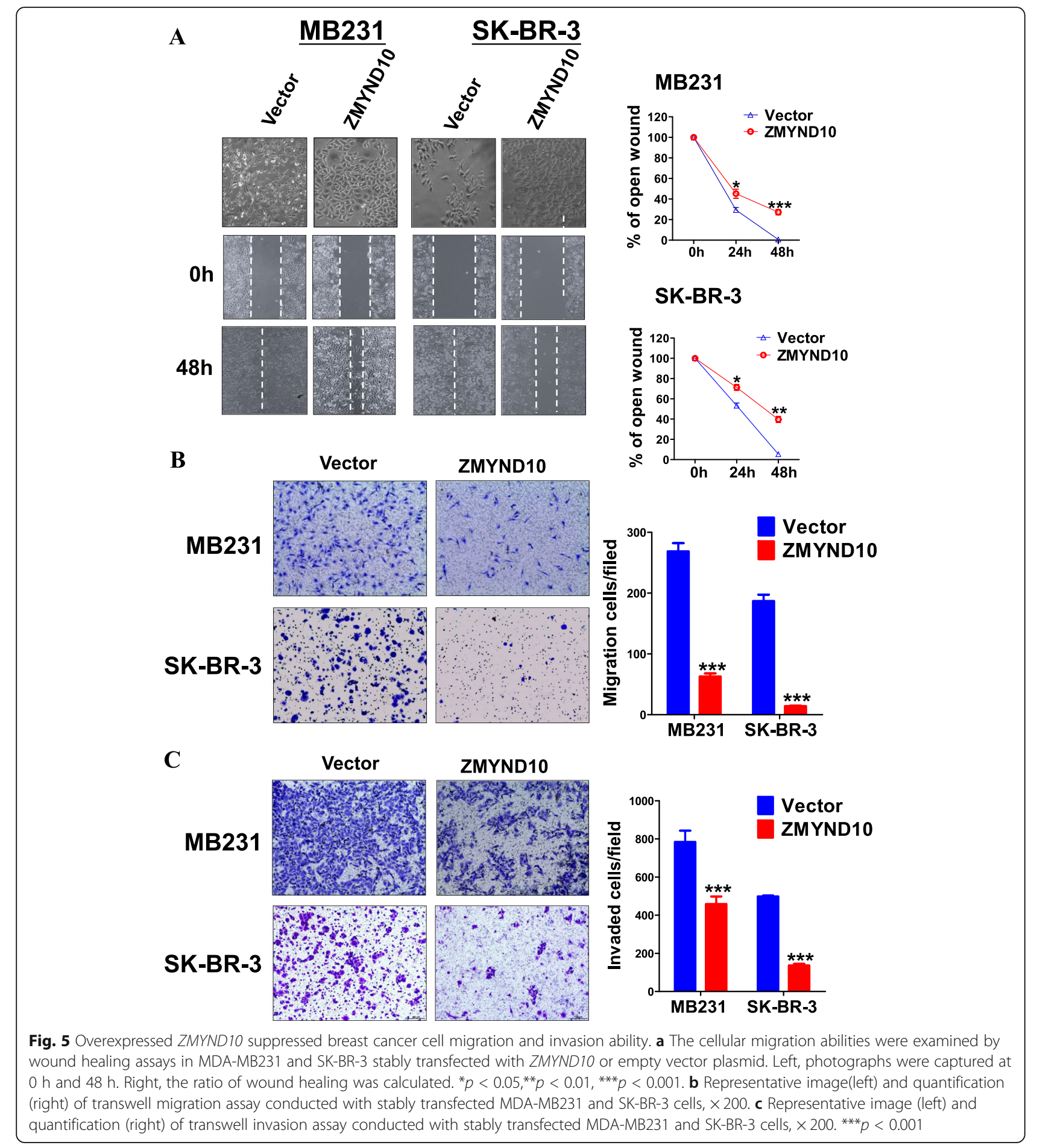

results suggested that ZMYND10 is able to suppress migration and invasion of breast cancer cells by inhibiting NEDD9 expression.

Mechanism for ZMYND10 regulation of NEDD9 expression Co-immunoprecipitation assay was performed but there was no direct interaction between ZMYND10 and
NEDD9 detected (data not shown). Thus, we focused on micro-RNA because micro-RNA might play an important role in gene inhibition and activation via a diverse series of mechanisms and may have vital effects on breast cancer progression [24]. Potential micro-RNA binding sites in the $3^{\prime}$-UTR of NEDD9 were first identified using a bioinformatics website (http://www. 

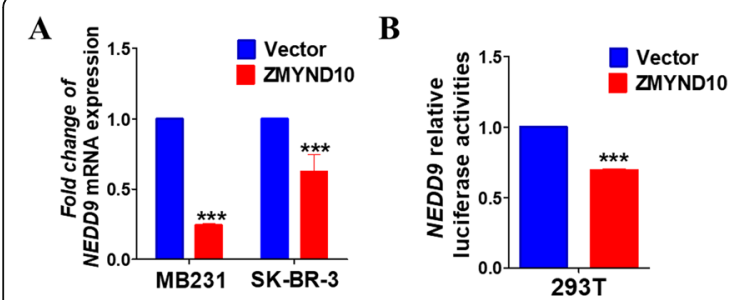

D

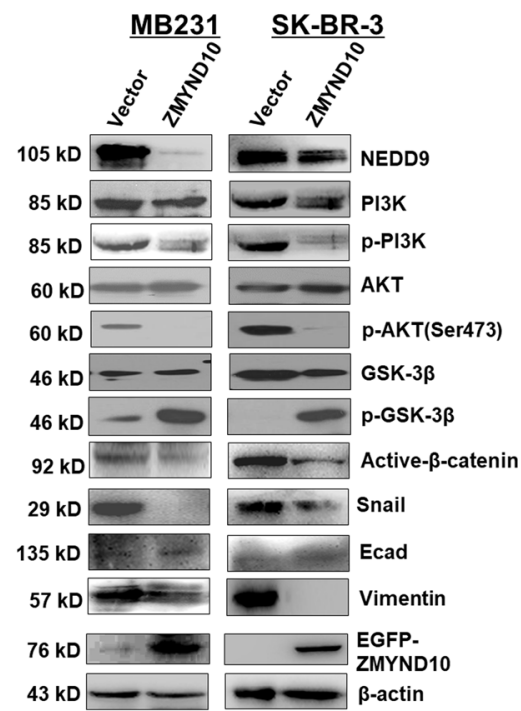

C
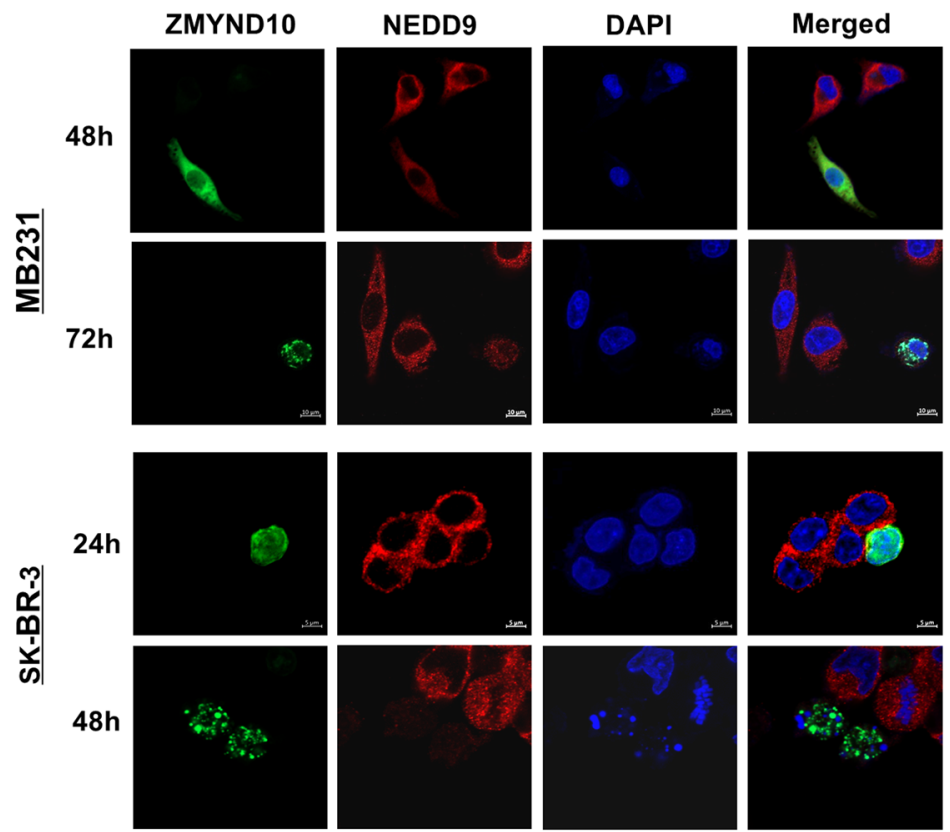

Fig. 6 Overexpressed ZMYND10 inhibited breast cancer metastasis via decreasing the expression of NEDD9. a The mRNA expression of NEDD9 was detected by qPCR. b Luciferase assay was performed to detect the regulation of ZMYND10 on NEDD9 in vector- and ZMYND10-expressed MDA-MB231 and SK-BR-3 cells. c Immunofluorescence showed the localization and expression of NEDD9 in MDA-MB231 and SK-BR-3 cells transfected with ZMYND10 plasmid. d After MDA-MB231 and SK-BR-3 cells were overexpressed with ZMYND10, the protein levels of NEDD9, PI3K,

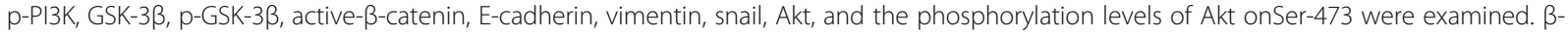
actin was used as an inner control

targetscan.org/) (Fig. 8), which was consistent with a report in lung cancer [25]. Indeed, ZMYND10 induced miR145-5p expression in MDA-MB231 and SK-BR-3 cells, which was detected by the qPCR (Fig. 8b). The luciferase reporter assay with the pmiR-RB-Report ${ }^{\mathrm{mm}}$ vector carrying MT or WT 3'-UTR sequences of $N E D D 9$ was used to validate the direct effect of miR145-5p on NEDD9 expression. The results showed that the miR-145-5p inhibitor inhibited miR-145-5p expression and induced the activity of WT3'-UTR but not MT3'-UTR reporter (Fig. 8c). The qPCR assay data showed that miR-145-5p inhibitor was added to ZMYND10-expressing breast cancer cells could reduce the expression of miR145-5p and increased the expression of NEDD9 (Fig. 8d, e). Consistent results were also confirmed at the protein level. The miR-145-5p inhibitor enhanced NEDD9 protein levels and partially reversed ZMYND10-decreased NEDD9 expression (Fig. 8f). Thus, ZMYND10 may inhibit the expression of $N E D D 9$ by upregulating miR-145-5p.
The ZMYND10/miR-145-5p axis promotes breast cancer cell migration and invasion by regulating the expression of NEDD9

In order to confirm whether miR-145-5p is a key mediator of ZMYND10 regulating NEDD9. We further investigated whether the effect of the ZMYND10-miR-145$5 \mathrm{p}-N E D D 9$ signaling axis on migration and invasion of breast cancer was sustained with the miR-145-5p inhibitor. While the miR-145-5p inhibitor enhanced NEDD9 protein levels and partially reversed ZMYND10-decreased NEDD9 expression, it enhanced cell migration and invasion and attenuated the inhibitory effect of $Z M Y N D 10$ decreased on migration and invasion (Fig. 9a, b). These data showed that the ZMYND10/miR145-5p/ $N E D D 9$ axis regulates the migration and invasion ability of breast cancer cells, which may contribute to breast cancer metastasis.

\section{ZMYND10 inhibits breast cancer growth in vivo}

To assess the role of ZMYND10 in suppressing breast tumor in vivo, a xenograft tumor model was established 


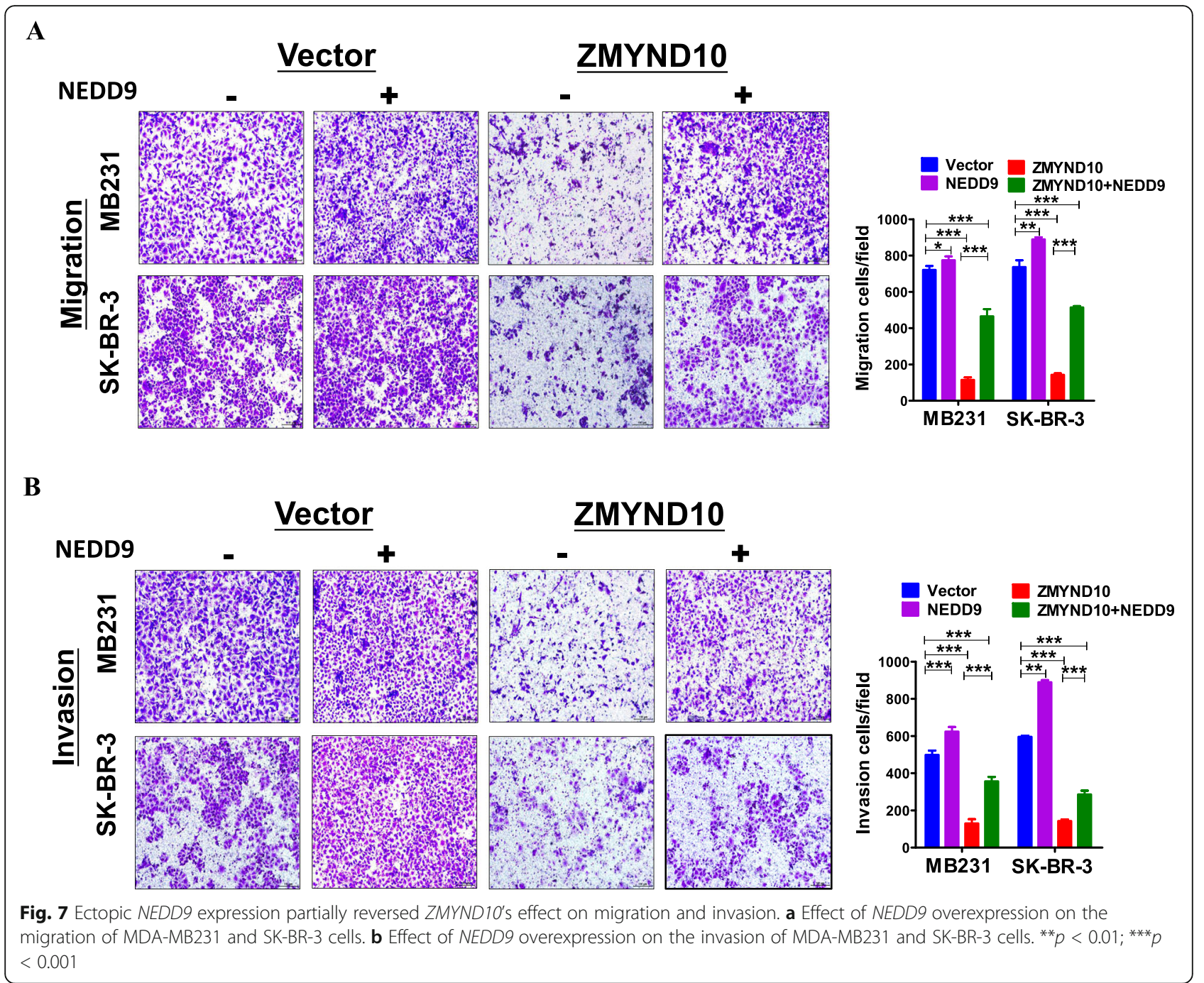

in nude mice. Tumor size and weight were significantly decreased in tumors derived from ZMYND10-expressing MDA-MB231 cells, as compared to mice injected mice with MDA-MB231 cells containing empty vector plasmids (Additional file 1: Figure S2A-C). The immunohistochemical assay showed that the proliferation markers Ki67 and NEDD9 were significantly reduced in the $Z M Y N D 10$-expressing tumors. (Additional file 1: Figure $\mathrm{S} 2 \mathrm{D})$. These data indicated that ZMYND10 plays an important role in inhibiting breast cancer in vivo, which is consistent with the previous results in vitro. The above results indicated that $Z M Y N D 10$ inhibits migration and invasion of breast cancer by suppressing NEDD 9 expression in vivo and in vitro.

\section{Discussion and conclusion}

Abnormal methylation of tumor suppressor gene promoter CpG islands has been established as a mechanism for transcriptional inactivation of tumor suppressor genes, which is important for the pathogenesis of malignant tumors including breast cancer [26, 27]. ZMYND10 is contained in a $630-\mathrm{kb}$ region in the $3 \mathrm{p} 21.3$, which is frequently and homozygously deleted in multiple cancer types as a result of promoter hypermethylation [28]. This region contains several tumor suppressor genes, such as RASSF1A, CACNA2D2, SEMA3B, and HYAL1 [5]. Consistent with the literature, ZMYND10 is an epigenetically regulated tumor suppressor gene and the hypermethylation of its promoter is associated with poor clinical prognosis in several cancer types. However, the function and molecular mechanism of ZMYND10 in breast cancer are still unknown. Here, we found that ZMYND10 is downregulated or silenced in breast cancer but not in normal breast and surgical-margin tissues. We also confirmed that promoter hypermethylation of $Z M Y N D 10$ is a major cause of its downregulation in breast cancer. Accordingly, ZMYND10 expression in $Z M Y N D 10$-silenced cells was restored by demethylation 
A

WT NEDD9 3' UTR(Position 47-54)5' ...ACGGUUACUAAGGAAAACUGGAA...3'
miR145-5p3' ...UCCCUAAGGACCCUUUUGACCUG
Mutant of NEDD9 3' UTR 5' ...ACGGUUACUAAGGAAAAGGUCAA...3'
B

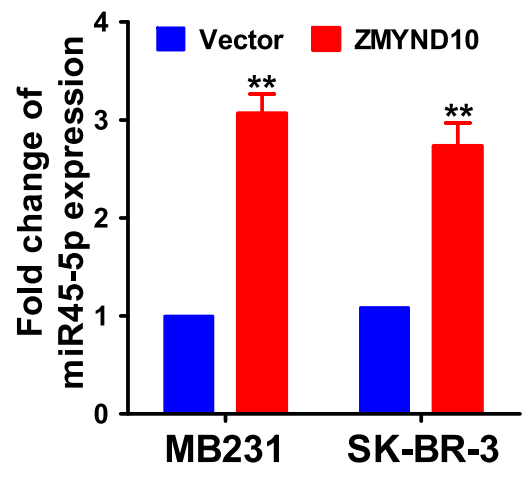

C

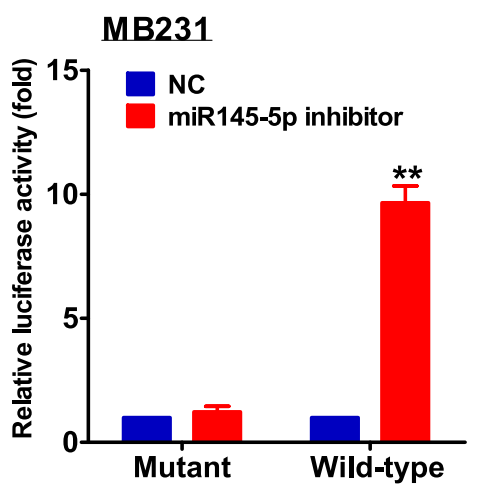

SK-BR-3

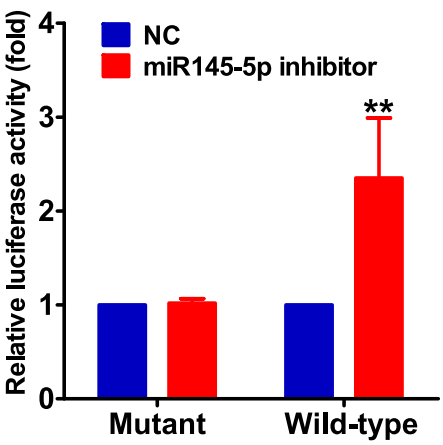

D

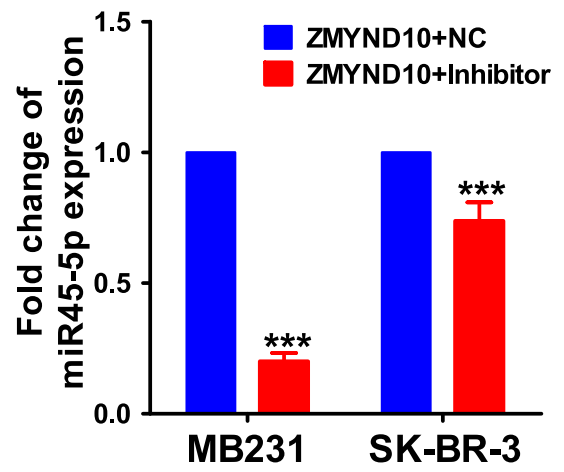

E

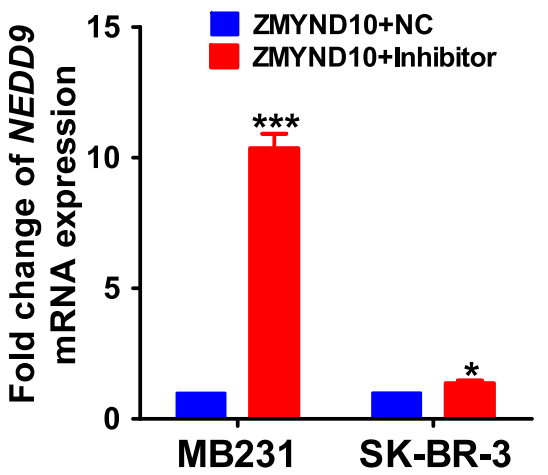

F

MB231

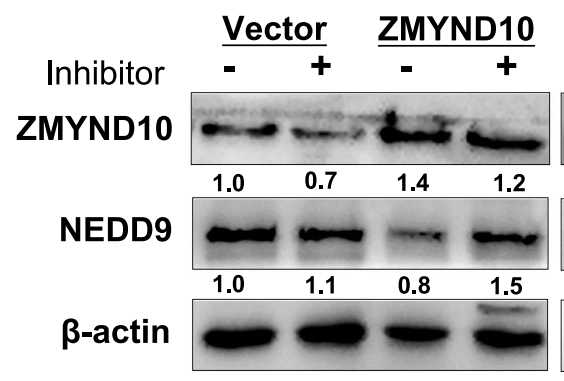

SK-BR-3
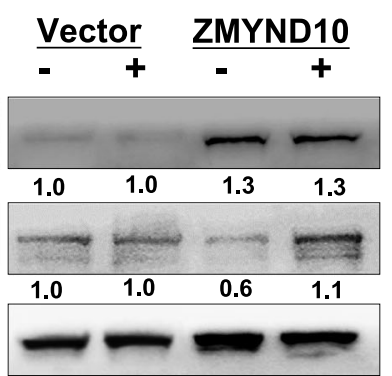

Fig. 8 ZMYND10 decreased the expression of NEDD9 via altering the miR-145-5p level. a Predicted duplex formation between human miR-145-5p and human wild type (WT) NEDD9 3'UTR. b The expression of miR145-5p was examined via qPCR in MDA-MB231 and SK-BR-3 cells transfected with vector or ZMYND10 plasmid. c Luciferase assay was performed to detect the regulation of miR-145-5p on WT and mutant of NEDD9-3'UTR in MDA-MB231and SK-BR-3 cells transfected with miR-NC or miR145-5p inhibitor oligo. d qPCR analysis for miR145-5p expression in MDA-MB231 and SK-BR-3 cells with ZMYND10+miR-NC or ZMYND10+ miR145-5p inhibitor. e qPCR analysis for NEDD9 expression in MDA-MB231 and SK-BR-3 cells with ZMYND10+miR-NC or ZMYND10+miR145-5p inhibitor. f Western blot assay was performed to detect the protein levels of NEDD9 in MDA-MB231 and SK-BR-3 cells transfected with p-EGFPC2, p-EGFPC2+ miR145-5p inhibitor, ZMYND10, and ZMYND10+ miR145-5p inhibitor. * $p<$ $0.05 ;{ }^{* *} p<0.01 ;{ }^{* * *} p<0.001$

treatment. ZMYND10 repressed breast cancer cell proliferation, promoted G2/M cell cycle arrest, apoptosis, and dramatically lessened migration and invasion of breast cancer cells in vitro. Moreover, ZMYND10 slowed down the growth of xenograft tumors in vivo. Overall,
ZMYND10 had strong tumor-suppressing effects in breast cancer cells both in vitro and in vivo.

As a potential tumor suppressor gene, ZMYND10 has been shown to promote apoptosis of tumor cells by regulating sMEK1 activity [15], and inhibition of angiogenesis. 


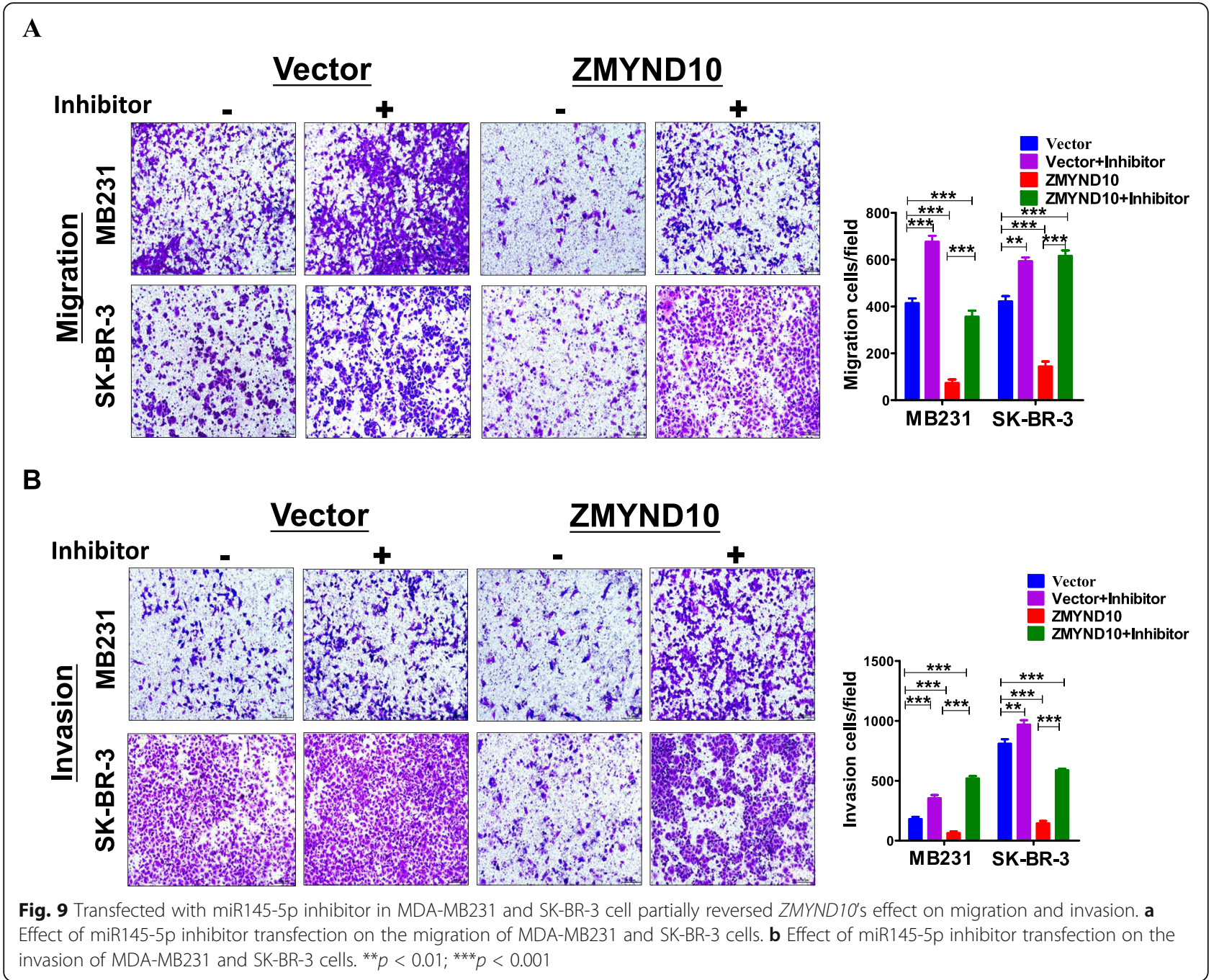

However, how ZMYND10 inhibits tumor metastasis remains unclear. So, we used RNA-sequence analysis to explore how $Z M Y N D 10$ performs its cellular functions. The screening results focused on genes and pathways associated with migration and adhesion. Further results indicated that cells overexpressing ZMYND10 have a poor invasion and migration ability, which confirmed that $Z M Y N D 10$ inhibited the invasion and migration of tumor cells. Particularly, we detected that ZMYND10 repressed the expression of $N E D D 9$, a pro-migration protein. Therefore, we concentrated on metastasis to illuminate the tumor inhibition mechanism of ZMYND10 and identified the miR-145-5p-NEDD9 signaling pathway downstream of ZMYND10NEDD9 was found to be closely related to breast cancer metastasis. There is abundant evidence that NEDD9 is an established marker of metastasis in multiple cancers, including breast cancer [21, 29-38]. NEDD9 was shown to restore the activity of $M M P 14$ by promoting the inactivation of Arf6 to facilitate breast cancer metastasis [21]. Other studies also confirmed that NEDD9 promotes
TNBC (triple-negative breast cancer) invasion by regulating the epithelial-mesenchymal transition [39]. However, no relationship has been reported with respect to the roles of ZMYND10 and NEDD9 in breast cancer development. We found that ZMYND10 significantly decreased the expression of NEDD9. In addition, restoring NEDD9 expression facilitated migration and invasion of the ZMYND10-expressing cells.

In the process of tumorigenesis and development, the expression of a variety of miRNAs changes, leading to corresponding changes in the expression of downstream target genes and affecting the tumor process [40]. NEDD9 was found to be regulated by miR145-5p by directly targeting the 3 '-UTR of NEDD9-mRNA in lung cancer [25]. miR145-5p expression was downregulated in breast cancer cells compared to normal human mammary cells, which was reversely correlated to the metastatic ability of breast cancer cells [41]. Therefore, we focused on miR145-5p to interpret the biological mechanism of ZMYND10 regulating the expression of 
NEDD9. Consistently, we showed that ZMYND10 downregulates the expression of NEDD9 through miR145-5p. Although we found that ectopic expression of ZMYND10 increased miR145-5p mRNA expression in MDA-MB231 and SK-BR-3 cells, the mechanism of ZMYND10-mediated miR-145-5p activation has not been fully determined.

Altogether, our study identified ZMYND10 as a tumor suppressor, which is downregulated in breast cancer due to its promoter hypermethylation, and suggested that ZMYND10 suppresses breast cancer metastasis by through the miR145-5p/NEDD9 signaling cascade. Whether this newly identified signaling pathway can be targeted for therapies against breast cancer deserve further studies.

\section{Methods}

Cell lines, plasmids, and tissue samples

Ten breast cancer cell lines (BT549, MDA-MB231, MCF7, T-47D

YCC-B1, YCC-B2, YCC-B3, ZR-75-1, MB468, SK-BR3) were kindly provided by Prof. Qian Tao (The Chinese University of Hong Kong). The cells were cultured in the RPMI 1640 medium supplemented with $10 \%$ fetal bovine serum (FBS, Gibco-BRL), $100 \mathrm{U} / \mathrm{mL}$ penicillin, and $100 \mathrm{mg} / \mathrm{mL}$ streptomycin (Gibco-BRL) and incubated in $5 \% \mathrm{CO}_{2}$ at $37{ }^{\circ} \mathrm{C}$. HEK293T cells were incubated in the DMEM medium (high glucose, HyClone, Logan, USA) with 10\% FBS. The pEGFPc2-ZMYND10 plasmid was constructed by cloning the entire amplified coding region of ZMYND10 into pEGFPc2 and sequenced for verification. The pEGFPc1-NEDD9 was constructed in a similar manner. Breast tissues were obtained from the Endocrine and Breast Surgery Department of the First Affiliated Hospital of Chongqing Medical University (Chongqing, China). Every sample was evaluated and subjected to histological diagnosis by expert pathologists. Every patient provided informed consent. Samples were stored at the Chongqing Medical University tissue bank until used in the study. This research was approved by the Institutional Review Board of the Chongqing Medical University(approval notice 20150302).

\section{Establishing stable cell lines}

MDA-MB231 and SK-BR-3 cells were cultured in six-well plates. pEGFPc2-ZMYND10 or pEGFPc2 was then transfected into $80 \%$ confluent MDA-MB231 and SK-BR-3 cells using Lipofectamine 2000 reagent (Lipofectamine 2000 Reagent, Invitrogen, CA, USA) according to the manufacturer's protocol. After transfection, cells were grown in a non-selective growth medium for $48 \mathrm{~h}$, after which it was replaced with a selection medium containing $24 \mu \mathrm{L} / \mathrm{mL}$ (MDA-MB231) and $10 \mu \mathrm{L} / \mathrm{mL}$ (SK-BR-3) G418 $(50 \mathrm{mg} / \mathrm{mL}$ ) for 14 days. Overexpression of ZMYND10 was confirmed by western blotting and quantitative realtime PCR (qPCR) before other experimental procedures.

\section{miRNA inhibitor and transfection}

The miR-145-5p inhibitor and negative control miRs (miR-NC) were synthesized by RIBOBIO (Guangzhou Ribobio Co., Ltd). All transfections were implemented using Lipofectamine 2000 according to the manufacturer's instructions with a concentration of $75 \mathrm{nM}$ miR145 inhibitor or miR-NC. Total RNA and protein were extracted $48 \mathrm{~h}$ post-transfection and used for quantitative real-time PCR (qPCR) and western blot analysis.

\section{DNA and RNA extraction}

Genomic DNA was isolated from $\mathrm{BrCa}$ tissues and cell lines using the QIAamp ${ }^{\circ}$ DNA Mini Kit (Qiagen, Hilden, Germany) and DNAzol ${ }^{\circ}$ Reagent (Invitrogen) following the manufacturer's instructions. Total RNA was separated from the $\mathrm{BrCa}$ tissues and cell lines using the TRIzol reagent (Invitrogen, Carlsbad, CA, USA). Total RNA and DNA were determined using gel electrophoresis. Samples were reserved at $-80^{\circ} \mathrm{C}$ until further use.

\section{Semiquantitative reverse transcription PCR and qPCR}

Reverse transcription was implemented using the Promega GoScript ${ }^{\text {th }}$ reverse transcriptase (Promega). Reverse transcription PCR (RT-PCR) was performed using the Go-Taq (Promega, Madison, WI, USA) and GeneAmp RNA PCR system (Applied Biosystems). $\beta$-actin was used as a control. SYBR Green (Thermo Fisher) and 7500 Real-Time PCR System (Applied Biosystems) were used to perform qPCR. GAPDH was amplified as a control. Primer sequences are listed in Table 1.

\section{5-Aza-2'-deoxycytidine and trichostatin A treatment}

Cells were treated with $10 \mu \mathrm{M}$ Aza (Sigma-Aldrich, St. Louis, MO, USA) for $72 \mathrm{~h}$ and then further treated with $100 \mathrm{nM}$ trichostatin A (TSA) (Cayman Chemical Co, Ann Arbor, MI, USA) for $24 \mathrm{~h}$. RNA was extracted for RT-PCR, and DNA was extracted for methylationspecific PCR(MSP).

\section{Bisulfite treatment, MSP, and qMSP}

Genomic DNA was extracted from tissues and cell lines using the QIAamp DNA Mini Kit (Qiagen, Hilden, Germany). DNA bisulfite treatment was carried out according to previously published methods [42]. MSP primers for $Z M Y N D 10$ are listed in Table 3. All primers were previously tested for their inability to amplify unbisulfite DNA. PCR products were analyzed on $2 \%$ agarose gels.qMSP was performed as previously described [43]. 
Table 3 List of PCR primers used in this study

\begin{tabular}{|c|c|c|c|c|c|}
\hline$\overline{P C R}$ & Primer & Sequence $\left(5^{\prime}-3^{\prime}\right)$ & Product size (bp) & PCR cycles & $\begin{array}{l}\text { Annealing } \\
\text { temperature }\left({ }^{\circ} \mathrm{C}\right)\end{array}$ \\
\hline \multirow[t]{6}{*}{ RT-PCR } & ZMYNDIOF & CTCGATATGGGAGACCTG & \multirow{2}{*}{$\begin{array}{l}\text { A.1.1.1.1.1.1.1. } \\
327 \mathrm{bp}\end{array}$} & \multirow{4}{*}{$\begin{array}{l}\text { A.1.1.1.1.1.1.2. } \\
32\end{array}$} & \multirow[t]{6}{*}{ A.1.1.1.1.1.1.3. 55} \\
\hline & ZMYNDIOR & CACCACCATGTAGATGGG & & & \\
\hline & NEDD9F & GCTGGATGGATGACTACGAT & \multirow{2}{*}{$\begin{array}{l}\text { A.1.1.1.1.1.1.4. } \\
145 \mathrm{bp}\end{array}$} & & \\
\hline & NEDD9R & AACAGCTGGAACTGGCTCAG & & & \\
\hline & GAPDHF & GGAGTCAACGGATTTGGT & \multirow{2}{*}{$\begin{array}{l}\text { A.1.1.1.1.1.1.5. } \\
\text { 206bp }\end{array}$} & \multirow{2}{*}{$\begin{array}{l}\text { A.1.1.1.1.1.1.6. } \\
23\end{array}$} & \\
\hline & GAPDHR & GTGATGGGATTTCCATTGAT & & & \\
\hline \multirow{10}{*}{$\begin{array}{l}\text { qRT- } \\
\text { PCR }\end{array}$} & ZMYNDIOF & CTAACTGAAACCCAGCCTCCTA & \multirow{8}{*}{$\begin{array}{l}\text { A.1.1.1.1.1.1.7. } \\
\text { 100bp }\end{array}$} & & \multirow[t]{10}{*}{ A.1.1.1.1.1.1.8. 60} \\
\hline & ZMYNDIOR & TTGCCTGCCACTTGCCTC & & & \\
\hline & miR-145-5pF & CTGATGGTGGAGAGCTCACA & & & \\
\hline & $M i R-145-5 p R$ & GTGCAGGGTCCGAGGT & & & \\
\hline & MiR-145-5pRT & $\begin{array}{l}\text { GTCGTATCCAGTGCAGGGTCCGAGGTATTCGCACTGGATACG } \\
\text { ACAGGGAT }\end{array}$ & & & \\
\hline & U6F & CTCGCTTCGGCAGCACA & & & \\
\hline & U6R & AACGCTTCACGAATTTGCGT & & & \\
\hline & U6RT & AACGCTTCACGAATTTGCGT & & & \\
\hline & GAPDHF & CCAGCAAGAGCACAAGAGGAA & \multirow[t]{2}{*}{$114 \mathrm{bp}$} & & \\
\hline & GAPDHR & CAAGGGGTCTACATGGCAACT & & & \\
\hline \multirow[t]{4}{*}{ MSP } & ZMYND10m1 & GGTTGTTGTTAGGATTCGTC & \multirow{2}{*}{$\begin{array}{l}\text { A.1.1.1.1.1.1.9. } \\
\text { 178bp }\end{array}$} & \multirow{2}{*}{$\begin{array}{l}\text { A.1.1.1.1.1.1.10. } \\
40\end{array}$} & \multirow[t]{2}{*}{ A.1.1.1.1.1.1.11. 60} \\
\hline & ZMYND10m2 & AACAATAACTCCGAAACTCCG & & & \\
\hline & ZMYND10u1 & TGGTTGTTGTTAGGATTGTT & \multirow{2}{*}{$\begin{array}{l}\text { A.1.1.1.1.1.1.12. } \\
181 \mathrm{bp}\end{array}$} & \multirow{2}{*}{$\begin{array}{l}\text { A.1.1.1.1.1.1.13. } \\
40\end{array}$} & \multirow[t]{2}{*}{ A.1.1.1.1.1.1.14. 58} \\
\hline & ZMYND10u2 & AAACAATAACTCCAAAACTCC A & & & \\
\hline \multirow[t]{2}{*}{ BGS } & ZMYNDIOBGS1 & GGGTAGGTTAAGATGTTATAGT & \multirow{2}{*}{$\begin{array}{l}\text { A.1.1.1.1.1.1.15. } \\
\text { 454bp }\end{array}$} & \multirow{2}{*}{$\begin{array}{l}\text { A.1.1.1.1.1.1.16. } \\
40\end{array}$} & \multirow[t]{2}{*}{ A.1.1.1.1.1.1.17. 60} \\
\hline & ZMYNDIOBGS2 & AACAACAACAATTCCAAATCTC & & & \\
\hline
\end{tabular}

Note: $R T-P C R$ semiquantitative reverse transcription $P C R, ~ q P C R$ quantitative real-time $P C R, M S P$ methylation-specific $P C R, B G S$ Bisulfite genomic sequencing

\section{Colony formation assay}

Cells stably expressing ZMYND10 or vector were plated at a number of different densities in fresh 6-well plates and incubated for 2 weeks with medium containing $10 \%$ FBS and G-418. Surviving colonies ( $\geq 50$ cells per colony) were counted after staining with crystal violet. Data were obtained from three independent cultures and each experiment was repeated in three separate wells.

\section{Cell proliferation assay}

Cell proliferation was evaluated with the CellTiter 96 AQueous One Solution Cell Proliferation Assay (MTS, Promega) according to the manufacturer's instructions. Cells stably expressing ZMYND10 or vector were seeded in 96-well plates (2000 cells per well) with $200 \mu \mathrm{L}$ of medium containing $10 \%$ FBS and cultured for 24,48 , or $72 \mathrm{~h}$. Cells were then incubated with $100 \mu \mathrm{L}$ of medium per well containing $20 \mu \mathrm{L}$ of the CellTiter 96 Aqueous One Solution reagent for $2 \mathrm{~h}$ at $37^{\circ} \mathrm{C}$. Absorbance values were measured at $450 \mathrm{~nm}$ with the microplate reader (Multiskan MK3, Thermo Fisher Scientific, Schwerte, Germany). Each experiment was repeated three times.
Flow cytometry analyses of cell cycle and apoptosis

For cell cycle analysis, cells were digested with trypsin and fixed with ice-cold $70 \%$ ethanol, treated with $5 \mathrm{mg} /$ $\mathrm{mL}$ RNase A (Sigma), stained with propidium iodide, and analyzed by flow cytometry (FACSCalibur instrument and CELLQUEST software, Becton Dickinson). For the apoptosis assays, cells were stained with annexin V-fluorescein isothiocyanate and PI (propidium iodide). Apoptosis and cell cycle status data were analyzed using the CELL Quest software (BD Biosciences, San Jose, CA, USA). All experiments were performed in triplicate.

\section{Wound healing assay}

Cells were seeded in six-well plates and allowed to grow until confluent. Following serum starvation of $24 \mathrm{~h}$, a linear scratch "wound" was created on the cell monolayer with a sterile $10-\mu \mathrm{L}$ tip. Cells were then washed with PBS (phosphate buffer saline), serum-free media were added, and microscopic cell images $(\times 10$ magnification) were collected every $6 \mathrm{~h}$. The linear "wound" was evaluated based on the zero-line. The experiment was performed three times in triplicate. 


\section{Transwell migration and invasion assay}

Transwell chamber inserts with $8-\mu \mathrm{m}$ pores and coated with $70 \mu \mathrm{L}$ of Matrigel $(2.5 \mathrm{mg} / \mathrm{mL}$; BD Biosciences Discovery Labware, 1:7 dilution) were used for the invasion assay. Cells were seeded into the upper wells of pre-coated transwell chambers. Lower wells of the transwell chambers were filled with $700 \mu \mathrm{L}$ of the same medium with $20 \%$ FBS. After a 48 -h incubation, cells were fixed with $4 \%$ paraformaldehyde for $30 \mathrm{~min}$ and then stained for $30 \mathrm{~min}$ with Crystal violet. Cells were then wiped off from the upper side of the filter using cotton swabs. Microphotograms of the cells that had migrated to the lower side of the filter were obtained using light microscopy.

\section{Immunofluorescence}

MDA-MB231 and SK-BR-3 cells were seeded on 24-well plates with microcover glass and then transfected with pEGFPc2-ZMYND10 plasmids for expression of the green fluorescent protein. After $48 \mathrm{~h}$, cells were fixed for $30 \mathrm{~min}$ in $4 \%$ paraformaldehyde, permeabilized with $0.5 \%$ Triton X-100 at room temperature for $10 \mathrm{~min}$, and then blocked with blocking buffer for $1 \mathrm{~h}$. After treatment, the slides were incubated with anti-HEF1 (NEDD9, 1:150; \#ab18056; Abcam, USA) at $4{ }^{\circ} \mathrm{C}$. After $20 \mathrm{~h}$, cells were incubated with Alexa Fluor 555conjugated goat anti-mouse secondary antibodies for $1 \mathrm{~h}$ in the dark. All slides were counterstained with 4'-6-diamidino-2-phenylindole (DAPI, Roche, Palo Alto, CA, USA). Photomicrographs were captured with a confocal laser scanning microscope.

\section{Western blot}

Cells were lysed using a protein extraction reagent (Thermo Scientific, Rockford, IL, USA) containing protease inhibitor phenyl methane sulfonyl fluoride and a phosphatase inhibitor cocktail (Sigma, St. Louis, MO, USA). Total protein concentrations were measured using the BCA protein assay reagent (Thermo Scientific, Rockford, IL, USA). Western blot assayswere implemented as previously described [43]. The primary antibodies were used as follows: ZMYND10 (\#S0437, Epitomics), p21( \#2947, Cell Signaling Technology), p27(\#3686, Cell Signaling Technology), Cyclin D1( \#sc-20044, , Santa Cruz Biotechnology), Bcl-xL(\#2764, Cell Signaling Technology), Bcl-2 (\#2870, Cell Signaling Technology), Bax ( \#5023, Cell Signaling Technology), cleaved caspase-3 (\#9664, Cell Signaling Technology), cleaved PARP(\#5625, Cell Signaling Technology), total AKT( \#4691, Cell Signaling Technology), Phospho-AKT (\#4060, Cell Signaling Technology), total PI3K(sc-423,Santa Cruz Biotechnology), Phosphor-PI3K( \#17366, Cell Signaling Technology),total GSK3ß \# \#315, Cell Signaling Technology), Phospho-GSK3 $\beta$ ( \#9323, Cell Signaling Technology), Snail ( \#3895, Cell Signaling Technology),Active- $\beta$-catenin(\#19807, Cell Signaling Technology) E-cadherin (
\#14472, Cell Signaling Technology),Vimentin ( \#5741,Cell Signaling Technology) and NEDD9 (\#ab18056, Abcam). $\beta$ actin ( \#sc-8432, Santa Cruz Biotechnology) served as a loading control. The intensity of the protein bands was gauged with ImageJ 1.52 version(NIH, Bethesda, MD, USA)

\section{In vivo tumor model}

The anti-tumor effect of the target gene was evaluated using an in vivo model. ZMYND10-and Vectorexpressing MDA-MB231 cells $\left(5 \times 10^{6}\right.$ in $0.2 \mathrm{~mL}$ of PBS) were injected subcutaneously into the right and left sides of the back in nude mice, respectively (female, aged 4-6 weeks, weighing 18-22 g, $n=4$ per group). All procedures for tumor model construction were approved by the Institute Ethics Committee of the First Affiliated Hospital of Chongqing Medical University (approval notice 20150302).

\section{Immunohistochemistry}

Standard streptavidin-peroxidase immunohistochemistry was performed using the UltraSensitive TM SP Kit (Maixin-Bio, Fujian, China) according to the manufacturer's instructions. Sections were dewaxed, rehydrated and blocked, and then incubated with primary antibodies against ZMYND10 (1:50 dilution, \#S0437, Epitomics) and Ki67 (1:100 dilution, \#ARG53222, Arigo) at $4{ }^{\circ}$ Covernight. The sections were then treated with a secondary antibody and stained with diaminobenzidine. IHC scores were determined according to previously published methods [44].

\section{Dual-luciferase reporter assay}

To verify NEDD9 as a direct target of miR-145-5p, target reporter plasmid containing wild-type (WT) and mutant (MT) NEDD9 3'-untranslated region (3'-UTR, Guangzhou Ribobio Co, Ltd., Guangzhou, China) was constructed. MDA-MB231 and SK-BR-3 cells were seeded in 24-well plates and co-transfected with WT or MT reporter plasmid and miR-145-5p inhibitor or miR$\mathrm{NC}$ according to the manufacturer's instructions. Luciferase activity was measured with a dual-luciferase reporter assay kit (Promega) after $48 \mathrm{~h}$. The regulation of NEDD 9 by $Z M Y N D 10$ was verified by luciferase reporter assay as previously described [43].

\section{Statistical analysis}

Statistical analyses were performed using GraphPad Prism 5.0 software and IBM SPSS 22.0 software. Twotailed Student's $t$ tests, the $\chi 2$ test, and Fisher's exact test were used to evaluate the experimental results. $p$ values of all tests were less than 0.05 , which was considered statistically significant. 


\section{Supplementary information}

Supplementary information accompanies this paper at https://doi.org/10. 1186/s13148-019-0785-z

Additional file 1: Figure S1. RNA-Sequence analysis of ZMYND10 overexpression in MDA-MB231 cells. (A)The whole distribution of differentially expressed genes in ZMYND10 stablely transfected MDA-MB231 cells were shown by volcanic map. (B)KEGG pathway classification of differentially expressed genes. The rich factor represents the proportion of differentially expressed genes in specific terms, and the size of the dots represents the number of relevant differentially expressed genes.The Q-value is a calibrated $p$-value. (C)The analysis of differentially expressed genes associated with adhesion is indicated as a heat map. Figure S2. ZMYND10 suppressed xenograft tumor growth in vivo. (A) Image before resection of tumor xenografts. Red round indicated ZMYND10-overexpressing tumors and blue round indicated empty vector control tumors. (B) Image after resection of tumor xenografts. (C) Tumor weight.(D) Representative images of immunohistochemical $(\mathrm{IHC})$ staining. Paraffin sections were stained for ZMYND10,Ki67 and NEDD9,400×magnification.

\section{Abbreviations}

A+T: 5-Aza-2'-deoxycytidine and trichostatin A (TSA); BA: Breast cancer adjacent tissues; BC: Breast cancer; BF: Breast fringe; BGS: Bisulfite genomic sequencing; BN: Breast normal tissue; DAPI: 4'-6-Diamidino-2-phenylindole; DEGs: Differentially expressed genes; DMFS: Distant-metastasis-free survival; EMT: Epithelial-mesenchymal transition; FBS: Fetal bovine serum; FDR: False discovery rate; GOBO: Gene Expression-Based Outcome for Breast Cancer Online; IHC: Immunohistochemistry; M: Methylated; miRNA: MicroRNA; miRNC: Negative control miRs; MSP: Methylation-specific polymerase chain reaction; MT: Mutant; PBS: Phosphate-buffered saline; PI: Propidium iodide; qMSP: Quantitative methylation-specific PCR; qPCR: Quantitative real-time PCR; RFS: Relapse-free survival; RNA-Seq: RNA-Sequencing; RTPCR: Semiquantitative reverse transcription PCR; TNBC: Triple-negative breast cancer; U: Unmethylated; WT: Wild-type

\section{Acknowledgements}

The authors thank Prof. Qian Tao (the Chinese University of Hong Kong, Hong Kong, China) for generously providing cell lines, primers, and plasmids.

\section{Authors' contributions}

YW, LD, QL, BS, FY, QX, and LZ have participated in methodology, investigation, and validation of data performed in this work. YW, XH, SH, ST, and $\mathrm{JH}$ are responsible of formal analysis of data. TX and $\mathrm{YW}$ wrote the original manuscript. TP, YL, and YF reviewed data and manuscript. TX and LL sourced the funding. All authors reviewed and approved the final version.

\section{Funding}

This study was supported by National Natural Science Foundation of China (\#81572769, \#81872380, \#81772869), Natural Science Foundation of

Chongqing (cstc2018jscx-mszdX0039), and National Key Research and Development Program of China (\#2017YFE0191700)

\section{Availability of data and materials}

All data supporting the results reported in the article is available from the corresponding author upon a reasonable request.

\section{Ethics approval and consent to participate}

Informed consent was obtained from each participant included in the study. Our experiments were approved by the Institutional Ethics Committees of the First Affiliated Hospital of Chongqing Medical University [approval notice \# 20150302], and the study methodologies conformed to the standards set by the Declaration of Helsinki.

\section{Consent for publication}

Not applicable.

\section{Competing interests}

The authors declare that they have no competing interests.

\section{Author details}

Key Laboratory of Molecular Oncology and Epigenetics, The First Affiliated Hospital of Chongqing Medical University, Chongqing, China. ${ }^{2}$ The People's Hospital of Tongliang District, Chongqing, China. ${ }^{3}$ Cancer Epigenetics Laboratory, Department of Clinical Oncology, State Key Laboratory of Translational Oncology, Sir YK Pao Center for Cancer, Li Ka Shing Institute of Health Sciences, The Chinese University of Hong Kong, Hong Kong, Hong Kong. ${ }^{4}$ Department of Pathology, Yong Loo Lin School of Medicine, National University of Singapore, Singapore, Singapore. ${ }^{5}$ Molecular Biology and Lung Cancer Program, Lovelace Respiratory Research Institute, Albuquerque, NM, USA.

Received: 17 August 2019 Accepted: 24 November 2019 Published online: 04 December 2019

\section{References}

1. Siegel RL, Miller KD, Jemal A. Cancer statistics, 2019. CA: a cancer journal for clinicians. 2019:69(1):7-34.

2. Li C, Yu C, Wang P. An age-period-cohort analysis of female breast cancer mortality from 1990-2009 in China. Int J Equity Health. 2015;14:76.

3. Di Cosimo S, Baselga J. Management of breast cancer with targeted agents: importance of heterogeneity. [corrected]. Nature reviews Clinical oncology. 2010;7(3):139-47.

4. Yau WL, Lung HL, Zabarovsky ER, Lerman MI, Sham JS, Chua DT, et al. Functional studies of the chromosome 3p21.3 candidate tumor suppressor gene BLU/ZMYND10 in nasopharyngeal carcinoma. International journal of cancer. 2006;119(12):2821-6.

5. Lerman Ml, Minna JD. The 630-kb lung cancer homozygous deletion region on human chromosome 3p21.3: identification and evaluation of the resident candidate tumor suppressor genes. The International Lung Cancer Chromosome 3p21.3 Tumor Suppressor Gene Consortium. Cancer Res. 2000;60(21):6116-33.

6. Zabarovsky ER, Lerman MI, Minna JD. Tumor suppressor genes on chromosome $3 p$ involved in the pathogenesis of lung and other cancers. Oncogene. 2002;21(45):6915-35.

7. Hesson L, Bieche I, Krex D, Criniere E, Hoang-Xuan K, Maher ER, et al. Frequent epigenetic inactivation of RASSF1A and BLU genes located within the critical 3p21.3 region in gliomas. Oncogene. 2004;23(13):2408-19.

8. Chiang YC, Chang MC, Chen PJ, Wu MM, Hsieh CY, Cheng WF, et al. Epigenetic silencing of BLU through interfering apoptosis results in chemoresistance and poor prognosis of ovarian serous carcinoma patients. Endocrine-related Cancer. 2013;20(2):213-27.

9. Tischoff I, Markwarth A, Witzigmann H, Uhlmann D, Hauss J, Mirmohammadsadegh A, et al. Allele loss and epigenetic inactivation of 3p21.3 in malignant liver tumors. Int J Cancer. 2005;115(5):684-9.

10. Yi Lo PH, Chung Leung AC, Xiong W, Law S, Duh FM, Lerman MI, et al. Expression of candidate chromosome 3p21.3 tumor suppressor genes and down-regulation of BLU in some esophageal squamous cell carcinomas. Cancer letters. 2006;234(2):184-92.

11. Agathanggelou A, Dallol A, Zochbauer-Muller S, Morrissey C, Honorio S, Hesson $L$, et al. Epigenetic inactivation of the candidate 3p21.3 suppressor gene BLU in human cancers. Oncogene. 2003;22(10):1580-8.

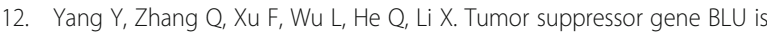
frequently downregulated by promoter hypermethylation in myelodysplastic syndrome. Journal of cancer research and clinical oncology. 2012:138(5):729-37.

13. Xiao K, Yu Z, Shi DT, Lei Z, Chen H, Cao J, et al. Inactivation of BLU is associated with methylation of Sp1-binding site of BLU promoter in gastric cancer. International journal of oncology. 2015;47(2):621-31.

14. Qiu GH, Tan LK, Loh KS, Lim CY, Srivastava G, Tsai ST, et al. The candidate tumor suppressor gene BLU, located at the commonly deleted region 3p21. 3 , is an E2F-regulated, stress-responsive gene and inactivated by both epigenetic and genetic mechanisms in nasopharyngeal carcinoma. Oncogene. 2004;23(27):4793-806

15. Dong SM, Byun HJ, Kim BR, Lee SH, Trink B, Rho SB. Tumor suppressor BLU enhances pro-apoptotic activity of sMEK1 through physical interaction. Cell Signalling. 2012;24(6):1208-14.

16. Zhang X, Liu H, Li B, Huang P, Shao J, He Z. Tumor suppressor BLU inhibits proliferation of nasopharyngeal carcinoma cells by regulation of cell cycle, cJun N-terminal kinase and the cyclin D1 promoter. BMC Cancer. 2012;12:267. 
17. Cheng Y, Ho RL, Chan KC, Kan R, Tung E, Lung HL, et al. Anti-angiogenic pathway associations of the 3p21.3 mapped BLU gene in nasopharyngea carcinoma. Oncogene. 2015;34(32):4219-28.

18. Yoo HJ, Kim BR, Byun HJ, Park SY, Rho SB. BLU enhances the effects of antiangiogenic activity in combination with gemcitabine-based chemotherapeutic agents. The international journal of biochemistry \& cell biology. 2013;45(7):1236-45.

19. Park ST, Byun HJ, Kim BR, Dong SM, Park SH, Jang PR, et al. Tumor suppressor BLU promotes paclitaxel antitumor activity by inducing apoptosis through the down-regulation of $\mathrm{BCl}-2$ expression in tumorigenesis. Biochemical and biophysical research communications. 2013; 435(1):153-9.

20. O'Neill GM, Seo S, Serebriiskii IG, Lessin SR, Golemis EA. A new central scaffold for metastasis: parsing HEF1/Cas-L/NEDD9. Cancer Res. 2007;67(19):8975-9.

21. Loskutov YV, Kozyulina PY, Kozyreva VK, Ice RJ, Jones BC, Roston TJ, et al. NEDD9/Arf6-dependent endocytic trafficking of matrix metalloproteinase 14: a novel mechanism for blocking mesenchymal cell invasion and metastasis of breast cancer. Oncogene. 2015;34(28):3662-75.

22. Zhou RT, He M, Yu Z, Liang Y, Nie Y, Tai S, et al. Baicalein inhibits pancreatic cancer cell proliferation and invasion via suppression of NEDD9 expression and its downstream Akt and ERK signaling pathways. Oncotarget. 2017;8(34):56351-63.

23. Tikhmyanova N, Golemis EA. NEDD9 and BCAR1 negatively regulate Ecadherin membrane localization, and promote E-cadherin degradation. PloS one. 2011;6(7):e22102.

24. Goh JN, Loo SY, Datta A, Siveen KS, Yap WN, Cai W, et al. microRNAs in breast cancer: regulatory roles governing the hallmarks of cancer. Biological reviews of the Cambridge Philosophical Society. 2016;91(2):409-28.

25. Yu W, Ding J, He M, Chen Y, Wang R, Han Z, et al. Estrogen receptor beta promotes the vasculogenic mimicry (VM) and cell invasion via altering the IncRNA-MALAT1/miR-145-5p/NEDD9 signals in lung cancer. Oncogene. 2018.

26. Jones PA, Takai D. The role of DNA methylation in mammalian epigenetics. Science. 2001;293(5532):1068-70.

27. Szyf M. DNA methylation signatures for breast cancer classification and prognosis. Genome medicine. 2012;4(3):26.

28. Hesson LB, Cooper WN, Latif F. Evaluation of the 3p21.3 tumour-suppressor gene cluster. Oncogene. 2007;26(52):7283-301.

29. Kim M, Gans JD, Nogueira C, Wang A, Paik JH, Feng B, et al. Comparative oncogenomics identifies NEDD9 as a melanoma metastasis gene. Cell. 2006; 125(7):1269-81.

30. Izumchenko E, Singh MK, Plotnikova OV, Tikhmyanova N, Little JL, Serebriiskii IG, et al. NEDD9 promotes oncogenic signaling in mammary tumor development. Cancer Res. 2009;69(18):7198-206.

31. Chang JX, Gao F, Zhao GQ, Zhang GJ. Role of NEDD9 in invasion and metastasis of lung adenocarcinoma. Experimental and therapeutic medicine. 2012;4(5):795-800

32. Speranza MC, Frattini V, Pisati F, Kapetis D, Porrati P, Eoli M, et al. NEDD9, a novel target of miR-145, increases the invasiveness of glioblastoma. Oncotarget. 2012;3(7):723-34.

33. Rousseau B, Jacquot C, Le Palabe J, Malleter M, Tomasoni C, Boutard T, et al. TP53 transcription factor for the NEDD9/HEF1/Cas-L gene: potential targets in Non-Small Cell Lung Cancer treatment. Sci Rep. 2015;5:10356.

34. Sima N, Cheng X, Ye F, Ma D, Xie X, Lu W. The overexpression of scaffolding protein NEDD9 promotes migration and invasion in cervical cancer via tyrosine phosphorylated FAK and SRC. PloS one. 2013;8(9):e74594.

35. Wang H, Mu X, Zhou S, Zhang J, Dai J, Tang L, et al. NEDD9 overexpression is associated with the progression of and an unfavorable prognosis in epithelial ovarian cancer. Human pathology. 2014;45(2):401-8.

36. Wang J, Wang S, Luan Y, Zhang W, Sun C, Cheng G, et al. Overexpression of NEDD9 in renal cell carcinoma is associated with tumor migration and invasion. Oncol Lett. 2017;14(6):8021-7.

37. Morimoto K, Tanaka T, Nitta Y, Ohnishi K, Kawashima H, Nakatani T. NEDD9 crucially regulates TGF-beta-triggered epithelial-mesenchymal transition and cell invasion in prostate cancer cells: involvement in cancer progressiveness. Prostate. 2014;74(8):901-10.

38. Zhang S, Wu L, Liu Q, Chen K, Zhang X. Impact on growth and invasion of gastric cancer cell lines by silencing NEDD9. OncoTargets and therapy. 2015;8:223-31.

39. Li P, Sun T, Yuan Q, Pan G, Zhang J, Sun D. The expressions of NEDD9 and E-cadherin correlate with metastasis and poor prognosis in triple-negative breast cancer patients. OncoTargets and therapy. 2016;9:5751-9.

40. Gebert LFR, MacRae IJ. Regulation of microRNA function in animals. Nature reviews Molecular cell biology. 2019;20(1):21-37.
41. Muti P, Sacconi A, Hossain A, Donzelli S, Ben Moshe NB, Ganci F, et al. Downregulation of microRNAs $145-3 p$ and $145-5 p$ is a long-term predictor of postmenopausal breast cancer risk: The ORDET prospective study. Cancer Epidemiol Biomarkers Prevention. 2014;23(11):2471-81.

42. Tao Q, Swinnen L, Yang J, Srivastava G, Robertson KD, Ambinder RF. Methylation status of the Epstein-Barr virus major latent promoter $C$ in iatrogenic B cell lymphoproliferative disease. Application of PCR-based analysis. The American journal of pathology. 1999;155(2):619-25.

43. Zhang Y, Fan J, Fan Y, Li L, He X, Xiang Q, et al. The new $6 q 27$ tumor suppressor DACT2, frequently silenced by CpG methylation, sensitizes nasopharyngeal cancer cells to paclitaxel and 5-FU toxicity via beta-catenin Cdc25c signaling and G2/M arrest. Clin Epigenet. 2018;10(1):26.

44. Li Y, Huang J, Zeng B, Yang D, Sun J, Yin X, et al. PSMD2 regulates breast cancer cell proliferation and cell cycle progression by modulating p21 and p27 proteasomal degradation. Cancer letters. 2018;430:109-22.

\section{Publisher's Note}

Springer Nature remains neutral with regard to jurisdictional claims in published maps and institutional affiliations.

Ready to submit your research? Choose BMC and benefit from:

- fast, convenient online submission

- thorough peer review by experienced researchers in your field

- rapid publication on acceptance

- support for research data, including large and complex data types

- gold Open Access which fosters wider collaboration and increased citations

- maximum visibility for your research: over $100 \mathrm{M}$ website views per year

At $\mathrm{BMC}$, research is always in progress.

Learn more biomedcentral.com/submissions 